Article

\title{
Concurrent Validity and Reliability of My Jump 2 App for Measuring Vertical Jump Height in Recreationally Active Adults
}

\author{
Špela Bogataj ${ }^{1,2}$, Maja Pajek ${ }^{2}$,, Slobodan Andrašić ${ }^{3, *}$ and Nebojša Trajković ${ }^{4}$ \\ Department of Nephrology, University Medical Centre, 1000 Ljubljana, Slovenia; spela.bogataj@kclj.si \\ Faculty of Sport, University of Ljubljana, 1000 Ljubljana, Slovenia; maja.pajek@fsp.uni-lj.si \\ Faculty of Economics, University of Novi Sad, 24000 Subotica, Serbia \\ 4 Faculty of Sport and Physical Education, University of Novi Sad, 21000 Novi Sad, Serbia; \\ nele_trajce@yahoo.com \\ * Correspondence: slobodan.andrasic@ef.uns.ac.rs; Tel.: +381-63-517-329
}

Received: 28 April 2020; Accepted: 27 May 2020; Published: 30 May 2020

check for updates

Featured Application: My Jump 2 app is a valid and reliable tool for the assessment of vertical jump in recreationally active participants. It is relatively easy to use, affordable, and portable. My Jump 2 can be used in different fields as an alternative to laboratory testing.

Abstract: This study aimed to examine the reliability, validity, and usefulness of the smartphone-based application, My Jump 2, against Optojump in recreationally active adults. Participants (18 women, $28.9 \pm 5.6$ years, and 26 men, $30.1 \pm 10.6$ years) completed squat jumps (SJ), counter-movement jumps (CMJ), and CMJ with arm swing (CMJAS) on Optojump and were simultaneously recorded using My Jump 2. To evaluate concurrent validity, jump height, calculated from flight time attained from each device, was compared for each jump type. Test-retest reliability was determined by replicating data analysis of My Jump 2 recordings on two occasions separated by two weeks. High test-retest reliability (Intraclass correlation coefficient (ICC) > 0.93) was observed for all measures in both male and female athletes. Very large correlations were observed between the My Jump 2 app and Optojump for SJ $(r=0.95, p=0.001), \mathrm{CMJ}(\mathrm{r}=0.98, p=0.001)$, and CMJAS $(\mathrm{r}=0.98, p=0.001)$ in male athletes. Similar results were obtained for female recreational athletes for all jumps $(r>0.94$, $p=0.001$ ). The study results suggest that My Jump 2 is a valid, reliable, and useful tool for measuring vertical jump in recreationally active adults. Therefore, due to its simplicity and practicality, it can be used by practitioners, coaches, and recreationally-active adults to measure vertical jump performance with a simple test as SJ, CMJ, and CMJAS.

Keywords: measurement; healthy athletes; jump performance; smartphones; My Jump 2; reliability; validity

\section{Introduction}

Physical fitness is important for older adults to maintain their independence and enhance wellbeing [1]. Therefore, it is of great importance to measure physical fitness in adults regularly. Vertical jump tests were recognized as the most common means for assessing physical fitness in various populations [2-4]. Moreover, a fundamental step in jump training studies is a vertical jump test. It is also a common method for assessing lower limb power in a physical education class, gym, or other sports programs [5]. Furthermore, it serves as an indicator of athletes fatigue during in-season [6]. Due to its simplicity and important outcome information, vertical jump tests are broadly used by 
coaches, strength and conditioning professionals, and professionals in health care. The most frequently used vertical jumps are squat jump (SJ), counter-movement jump (CMJ), and drop jump (DJ).

The most commonly used instruments for measuring the vertical jump characteristics have been photoelectric cell systems, force platforms, linear position transducers, infrared cells, contact mats, and video recording [7-12]. The great majority of mentioned instruments presents good validity and reliability in measuring different jumps with the force plate considered as the "gold standard". However, most of the above-mentioned instruments are not cheap and not widely accessible for different populations. Accordingly, due to the fact that these tools are expensive and not easy for transport, practical value for measuring vertical jumps in recreationally active adults is questionable.

Technology improvements led to the integration of high-speed cameras in mobile phones. The mobile application My Jump 2 takes advantage of these cameras to record slow-motion videos of different jump tasks. It gives us information about jump height by selecting the take-off and landing frame. Its validity and reliability were previously reported in male sport science students for drop jumps [8], elderly people [13], and in professional cerebral palsy football players for SJ and CMJ [14]. To the authors' knowledge, there is only one study [15] that analyzed the concurrent validity and reliability of a My Jump app for measuring vertical jump in recreationally active adults. However, the participants were younger men (22 years), and only CMJ was evaluated. There is evidence that the reliability of jumping explosiveness in physical performance tests might vary between men and women [16]. Therefore, it is necessary to check the validity and reliability of the My Jump app with recreational male and female adults. Moreover, in the study mentioned above, My Jump has recorded videos with iPhone $5 \mathrm{~s}$ app at $120 \mathrm{fps}$. As mentioned earlier, the key limiting factor to the accuracy of the app is the frame rate [8]. Therefore, the $240 \mathrm{fps}$ camera on iPhone $X$ was expected to make a significant improvement in the app's performance regarding reliability and validity.

Due to smartphone apps popularity, portability, affordability, and advanced technology, it is important to check the accuracy of these apps for measuring variables related to physical performance and health. Therefore, the present study aimed to investigate the reliability, validity, and usefulness of the My Jump 2 app in comparison to reliable and validated Optojump photoelectric cells system in measuring SJ, CMJ, and CMJ with arm swing (CMJAS) in recreationally active adults. The current research covered a heterogeneous sample with a bigger age range as contrasting to the homogeneous sample in most studies. Our goal was to reassess the app validity in a more heterogeneous sample that has diverse jumping capabilities in order to overcome possible errors in measurements.

\section{Materials and Methods}

\subsection{Participants}

A total of 44 participants volunteered to partake in the research. The sample consisted of 18 women (age $-28.9 \pm 5.6$ years; height $-169.6 \pm 6.2 \mathrm{~cm}$; weight $-60.5 \pm 8.7 \mathrm{~kg}$ ) and 26 men (age $-30.1 \pm 10.6$ years; height $-178.2 \pm 16.2 \mathrm{~cm}$; weight $-85.9 \pm 23.8 \mathrm{~kg}$ ) who were recreationally active and had membership in the local gym in Subotica, Serbia where the testing was performed. Participants completed general health and demographic survey and were excluded if they had a history of diseases, injuries in the past six months, or physical condition that may affect testing. All participants were asked if they regularly participated in vigorous physical activity and about the type of activity. Additionally, data were collected regarding the training background and training frequency during one week. On the day of testing, they were healthy, without any heart or pulmonary disease, and injury-free. Before the testing, they were not involved in any strength, jumping, or high-intensity training for $48 \mathrm{~h}$. They were informed about the testing procedures, and before the start, they signed written informed consent. The research adhered to the Declaration of Helsinki and was approved by the local ethics committee (ref. 12/1041). 


\subsection{Procedures}

All participants were familiarized with SJ, CMJ, and CMJAS techniques one day before testing at the same place where the testing was conducted. Assistants also have introduced the participants with the proper technique before testing by video and live demonstration and the explanation of the correct technique.

Before testing, they carried out a standardized 10 min warm-up that consisted of lower-body dynamic stretches, jogging, skipping, and vertical jumps based on similar jump warm-up protocols used in previous studies [15,17]. Their body mass was measured to the nearest $0.1 \mathrm{~kg}$ with electronic scale TANITA BC 540 (TANITA Corp., Arlington Heights, IL, USA) and body height with a stadiometer (SECA Instruments Ltd., Hamburg, Germany) to the nearest $1 \mathrm{~cm}$. The leg length and height with bended knees at about $90^{\circ}$ were measured using a measuring tape to the nearest $1 \mathrm{~cm}$. Leg length was measured from the anterior iliac spine to the tiptoe in the laying position. Height at $90^{\circ}$ was measured vertically from the anterior iliac spine to the ground in an optimal jump performance position (the angle at approximately $90^{\circ}$ ). Then, each participant performed three SJs, three CMJs, and three CMJs free arms with the instruction to jump as high as possible. For all jumps, it was recommended that the participants leave the floor at take-off with the knees and ankles extended and land in a similarly extended position [18]. Between the trials, there was a two-minute passive rest. The highest jump of each technique was taken into analysis. The jumps were recorded with the Optojump photoelectric cell system (Optojump photocell system; Microgate, Bolzano, Italy) and with an iPhone X (Apple Inc., Cupertino, CA, USA) through My Jump 2 app at the same time. The participants repeated the testing procedure after two weeks with the same conditions and in the same order as during the first testing.

Squat jump performance [19]

Participants were instructed to start the jump in the position of $90^{\circ}$ knee flexion with the feet shoulder-width apart and with their hands on their waist. They were asked to jump for maximum height and maintain their hand on the waist. Counter-movement was discouraged, and in case of any mistake, the jump was repeated.

Counter-movement jump performance [20]

The CMJ starting position was a standing position with a straight torso and knees fully extended with the feet shoulder-width apart. Participants were asked to keep their hands on their waist throughout the whole jump. They were instructed to perform a quick downward movement (approximately $90^{\circ}$ of knee flexion), and afterward a fast upward movement to jump as high as possible.

Counter-movement jump free arms performance

The CMJAS technique is similar to CMJ with the exception of arm movement. Participants were instructed to swing back with their arms during downward movement and forward during upward movement.

\section{Optojump photoelectric cell system}

The Optojump system consists of two parallel bars placed approximately $1 \mathrm{~m}$ apart and parallel to each other (see Figure 1). The bars are equipped with 33 optical light-emitting diodes (LEDs) with continuous communication of the transmitting and the receiving bar. The LEDs are positioned $0.3 \mathrm{~cm}$ from the ground level and at a $3.125 \mathrm{~cm}$ interval. The height of the jump is calculated as follows: $\mathrm{h}=0.5 \mathrm{~g} \times \mathrm{t}^{2}$, where $\mathrm{h}$ is the height of the jump, $\mathrm{g}$ is the acceleration of gravity, $\mathrm{t}$ is half of the flight time.The Optojump achieved strong concurrent validity for jump height in comparison with the force platform $(\mathrm{ICC}=0.99 ; 95 \% \mathrm{CI}$ (confidence interval) $=0.97 ; 0.99 ; p<0.001)$ and was recognised as an reliable instrument for field-based vertical jump assessments [18]. 


\section{My Jump 2 app}

The app My Jump 2 for iPhone $X$ was used to calculate the jump height by manually selecting the take-off frame and landing frame (Figure 1) of the video. The app determines the jump height using the equation $\mathrm{h}=\mathrm{t}^{2} \times 1.22625$ described by Bosco et al. [21] where $h$ stands for the jump height (in meters) and $t$ for flight time (in seconds). All collections were made with the same phone and by the same evaluator with no professional experience in video analysis. The evaluator was always recording from the same position (approximately $1 \mathrm{~m}$ height) and with the same distance from the participants (approximately $1.5 \mathrm{~m}$ ), enabling the clear view of participants lower limbs. We used the sagittal plane because it showed that identification of the exact take-off and landing frames was more easily viewed, compared to a frontal plane view [22].
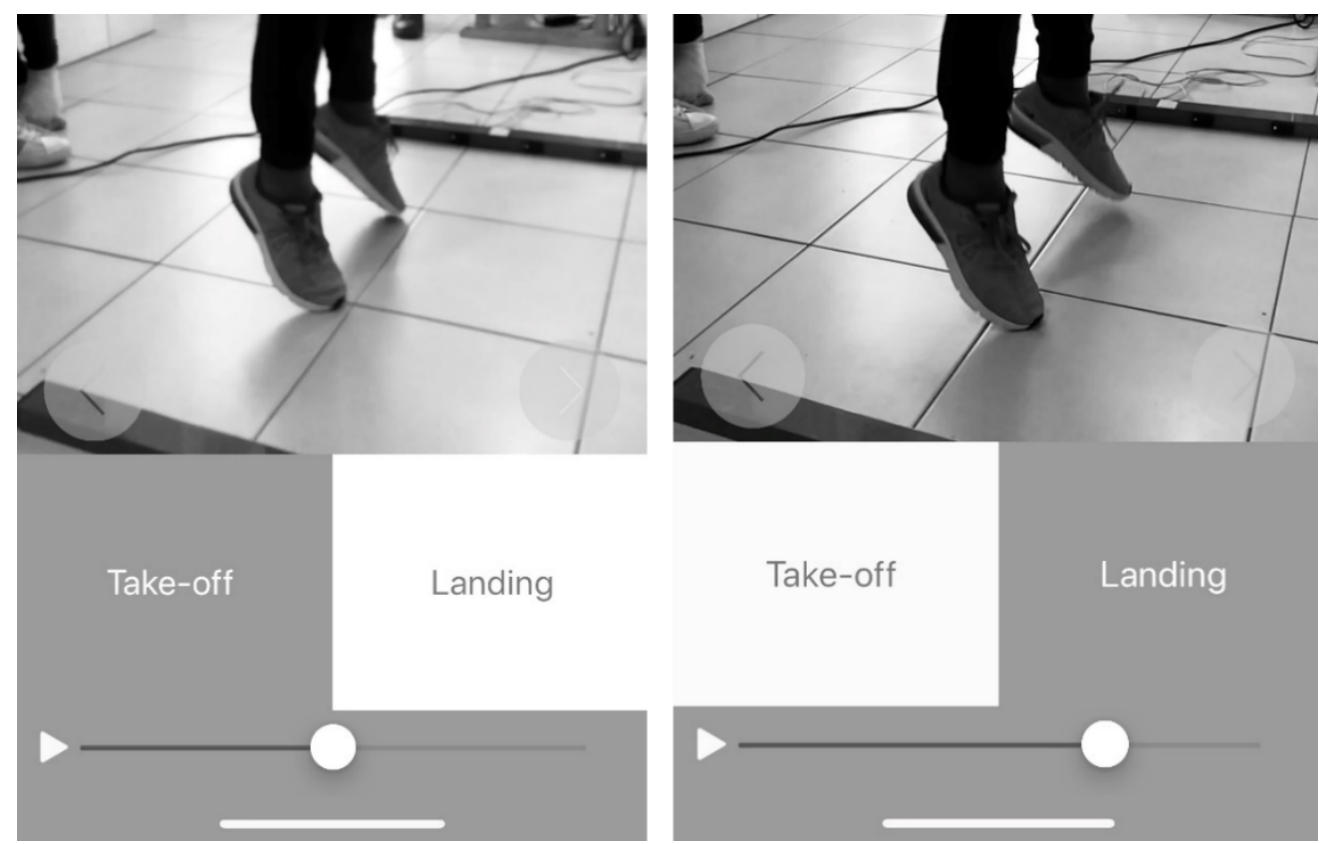

Figure 1. Take-off and landing phase frames on My Jump 2 app.

\subsection{Statistical Analysis}

Descriptive statistics were presented using means and standard deviations. Shapiro-Wilk test was used to check the data normality. Systematic bias between sessions and tools was evaluated using the paired samples $t$-test [18]. Standardized differences in mean (with 95\% confidence intervals; $\mathrm{CI}$ ) were calculated to determine the magnitude of the change across and between tests. According to Hopkins et al. [16], Cohen d effect size (ES) magnitudes of change were classified as trivial $(>0.2)$, small (0.2-0.5), moderate $(0.5-0.8)$, large $(0.8-1.60)$, and very large $(>1.60)$. Reliability between test-retest was analyzed using intraclass correlation coefficient (ICC), typical error (TE) expressed as coefficient of variation (CV\%), and smallest worthwhile change (SWC) according to Excel spreadsheet provided by Hopkins (2007) [23]. Regarding the ICC analysis, a single measure, two-way mixed, absolute-agreement parameter was used [24]. The highest jump from each subject on both testing sessions, retrieved from the My Jump 2, was used. ICC was interpreted as $<0.1=$ low,$<0.3=$ moderate, $<0.5=$ high,$<0.7=$ very high,$<0.9=$ nearly perfect, and $<1.0=$ perfect. A good reliability was considered if following criteria was fulfilled: $\mathrm{CV}<5 \%$ and ICC $>0.69$ [25]. Test usefulness was determined based on the comparison of SWC $(0.2$ multiplied by the between-subject SD, based on Cohen's ES) to TE [26]. The following criteria were used to establish the usefulness of tests: "Marginal" (TE > SWC), “OK" (TE = SWC), and "Good" (TE < SWC).

The concurrent validity of the app was tested with Pearson's product-moment correlation coefficient (r). Additionally, the agreement between Optojump and My Jump 2 data was then examined 
graphically using Bland and Altman's plots in which the difference between both devices was plotted against the mean of the two devices [27].

\section{Results}

Participants' descriptive characteristics are presented in Table 1.

Table 1. Descriptive characteristics.

\begin{tabular}{ccc}
\hline & Male $(\mathbf{n}=\mathbf{2 6})$ & Female $(\mathbf{n}=\mathbf{1 8})$ \\
\hline Age (years) & $30.1 \pm 10.6$ & $28.9 \pm 5.6$ \\
Height $(\mathrm{cm})$ & $178.2 \pm 16.2$ & $169.6 \pm 6.2$ \\
Weight $(\mathrm{kg})$ & $85.9 \pm 23.8$ & $60.5 \pm 8.7$ \\
Leg length $(\mathrm{cm})$ & $108.1 \pm 4.7$ & $106.1 \pm 4.5$ \\
Years of training & $10.5 \pm 7.6$ & $9.8 \pm 6.6$ \\
Training hours per week & $6.2 \pm 2.1$ & $3.9 \pm 1.1$ \\
\hline
\end{tabular}

Note: Values are expressed as mean $\pm \mathrm{SD}$.

\subsection{Reliability}

Similar SJ (test $=29.6 \pm 6.0 \mathrm{~cm}$; retest $=30.8 \pm 6.6 \mathrm{~cm}), \mathrm{CMJ}($ test $=31.9 \pm 6.6$; retest $=34.2 \pm 6.9 \mathrm{~cm})$ and CMJAS (test $=39.4 \pm 9.7 \mathrm{~cm}$; retest $=39.7 \pm 10.0 \mathrm{~cm}$ ) values were observed between testing sessions in male recreationally active adults. Non-significant differences $(p>0.05)$ were observed between testing sessions for SJ (ES = trivial; CI 95\% (0.4; 2.1)), CMJ (ES = small; CI 95\% (1.6; 2.9)), and CMJAS $($ ES = trivial; CI 95\% $(-0.5 ; 1.1))$ as observed in Table 2 . High test-retest reliability $($ ICC $>0.93 ;$ TE $<5 \%$ for CMJ and CMJAS, respectively) was observed for all measures.

Table 2. Test-retest reliability and usefulness of My Jump 2 in male recreationally active adults.

\begin{tabular}{cccc}
\hline & SJ & CMJ & CMJAS \\
\hline Test (cm) & $29.6 \pm 6.0$ & $31.9 \pm 6.6$ & $39.4 \pm 9.7$ \\
Retest (cm) & $30.8 \pm 6.6$ & $34.2 \pm 6.9$ & $39.7 \pm 10.0$ \\
ES & $0.19($ trivial) & $0.34($ small) & 0.03 (trivial) \\
Diff (95\% CI) & $1.2(0.4 ; 2.1)$ & $2.3(1.6 ; 2.9)$ & $0.3(-0.5 ; 1.1)$ \\
ICC (95\% CI) & $0.93(0.86 ; 0.96)$ & $0.96(0.93 ; 0.97)$ & $0.97(0.95 ; 0.99)$ \\
TE (95\% CI) & $1.8(1.5 ; 2.3)$ & $1.3(1.1 ; 1.7)$ & $2.0(1.6 ; 2.6)$ \\
CV\% (95\% CI) & $5.8(4.7 ; 7.6)$ & $4.1(3.4 ; 5.5)$ & $5.0(4.0 ; 6.6)$ \\
SWC\% & $1.2(4.3 \%)$ & $1.3(4.0 \%)$ & $2.0(5.3 \%)$ \\
Rating & marginal & OK & OK
\end{tabular}

Abbreviations: SJ, squat jump; CMJ, countermovement jump; ES, effect size; Diff, difference; CI, confidence interval; ICC, intraclass correlation coefficient; $\mathrm{TE}$, typical error; $\mathrm{CV}$, coefficient of variation; $\mathrm{SWC}$, smallest worthwhile change.

Table 3 shows the test retest results for SJ (test $=23.9 \pm 6.0 \mathrm{~cm}$; retest $=25.8 \pm 6.8 \mathrm{~cm}$ ), $\mathrm{CMJ}($ test $=26.8 \pm 6.3$; retest $=27.3 \pm 6.2 \mathrm{~cm})$, and CMJAS (test $=29.3 \pm 6.0 \mathrm{~cm}$; retest $=30.2 \pm 6.4 \mathrm{~cm})$ in female recreationally active adults. There were no significant differences $(p>0.05)$ between testing sessions for SJ (ES = small; CI 95\% (1.0; 2.8)), CMJ (ES = trivial; CI 95\% (-0.1; 1.1)), and CMJAS (ES = trivial; CI 95\% (0.2; 1.6)). High test-retest reliability (ICC > 0.94; TE < 5\% for CMJ and CMJAS, respectively) was observed for all measures.

\subsection{Test Usefulness}

The TE for SJ for both male and female participants was greater than the presumed SWC; consequently, these measures were rated as "marginal." In contrast, TE for CMJ and CMJAS for both genders were similar or lower than SWC and was rated as "OK" and "good". 
Table 3. Test-retest reliability and usefulness of My Jump 2 in female recreationally active adults.

\begin{tabular}{cccc}
\hline & SJ & CMJ & CMJAS \\
\hline Test (cm) & $23.9 \pm 6.0$ & $26.8 \pm 6.3$ & $29.3 \pm 6.0$ \\
Retest (cm) & $25.8 \pm 6.8$ & $27.3 \pm 6.2$ & $30.2 \pm 6.4$ \\
ES & $0.30($ small) & $0.08($ trivial) & 0.15 (trivial) \\
Diff (95\% CI) & $1.90(1 ; 2.8)$ & $0.5(-0.1 ; 1.1)$ & $0.9(0.2 ; 1.6)$ \\
ICC (95\% CI) & $0.94(0.86 ; 0.97)$ & $0.97(0.93 ; 0.98)$ & $0.97(0.92 ; 0.98)$ \\
TE (95\% CI) & $1.6(1.3 ; 2.3)$ & $1.1(0,8 ; 1.5)$ & $1.2(0.9 ; 1.6)$ \\
CV\% (95\% CI) & $7.2(5.6 ; 10.3)$ & $4.3(3.4 ; 6.1)$ & $4.3(3.3 ; 6.0)$ \\
SWC\% & $1.3(5.1 \%)$ & $1.2(4.5 \%)$ & $1.2(4.2 \%)$ \\
Rating & marginal & good & OK \\
\hline
\end{tabular}

\subsection{The Validity of the Test}

There were no significant differences $(p>0.05)$ between the My Jump 2 app and Optojump for all jumps in male participants with trivial effects size (from -0.03 to -0.09 ) (Table 4 ). Very large correlations were observed between the My Jump 2 app and Optojump for SJ $(r=0.95, p=0.001), C M J(r=0.98$, $p=0.001)$, and CMJAS $(\mathrm{r}=0.98, p=0.001)$.

Table 4. Descriptive statistics and validity analysis in male recreationally active adults based on Pearson's r.

\begin{tabular}{ccccccc}
\hline & My Jump 2 & Optojump & Diff. (95\% CI) & ES & r (95\% CI) & Rating \\
\hline SJ & $29.6 \pm 6.0$ & $30.0 \pm 6.3$ & $0.40(-3.26 ; 2.46)$ & -0.07 & $0.95(0.91 ; 0.97)$ & Very large \\
CMJ & $31.9 \pm 6.6$ & $32.5 \pm 7.1$ & $0.60(-3.79 ; 2.59)$ & -0.09 & $0.98(0.95 ; 0.99)$ & Very large \\
CMJAS & $39.4 \pm 9.7$ & $39.7 \pm 9.5$ & $0.30(-4.76 ; 4.16)$ & -0.03 & $0.98(0.97 ; 0.99)$ & Very large \\
\hline
\end{tabular}

Abbreviations: $r$, Pearson's correlation coefficient.

Similar results were obtained for female recreationally active adults (Table 5). No significant differences $(p>0.05)$ were observed between the My Jump 2 app and Optojump for all jumps in female recreational athletes with trivial effects size (from -0.09 to -0.19 ). Very large correlations were observed between the My Jump 2 app and Optojump for all jumps $(\mathrm{r}>0.94, p=0.001)$.

Table 5. Descriptive statistics and validity analysis in female recreationally active adults based on Pearson's r.

\begin{tabular}{ccccccc}
\hline & My Jump 2 & Optojump & Diff. (95\% CI) & ES & r (95\% CI) & Rating \\
\hline SJ & $23.9 \pm 6.0$ & $24.5 \pm 7.5$ & $0.6(-3.79 ; 2.59)$ & -0.09 & $0.97(0.93 ; 0.99)$ & Very large \\
CMJ & $26.8 \pm 6.3$ & $27.7 \pm 7.8$ & $0.9(-4.90 ; 3.10)$ & -0.13 & $0.96(0.91 ; 0.98)$ & Very large \\
CMJAS & $29.3 \pm 6.0$ & $30.7 \pm 8.4$ & $1.4(-5.51 ; 2.71)$ & -0.19 & $0.94(0.87 ; 0.98)$ & Very large \\
\hline
\end{tabular}

Figures 2-4 show the level of agreement for all jumps. Bland and Altman's plot depicting limits of agreement for SJ height between the Optojump and My Jump 2 show that the majority of data points are within the $95 \%$ CI's (Figure 2).

Further analysis of the Bland-Altman plots in male athletes revealed very low $R^{2}$ values $\left(R^{2} \leq 0.10\right)$, meaning outcomes estimated from My Jump 2 had no predisposition to overestimate or underestimate jump performance. On the contrary, in female participants, the plot shows bias related to the magnitude of jump height $\left(R^{2}=0.74\right)$, such that, at lower jump heights, values derived from Optojump data tended to be higher than those from My Jump 2, resulting in positive difference scores. Moreover, the mean bias between the two methods for all jumps was $0.51 \mathrm{~cm}$. 

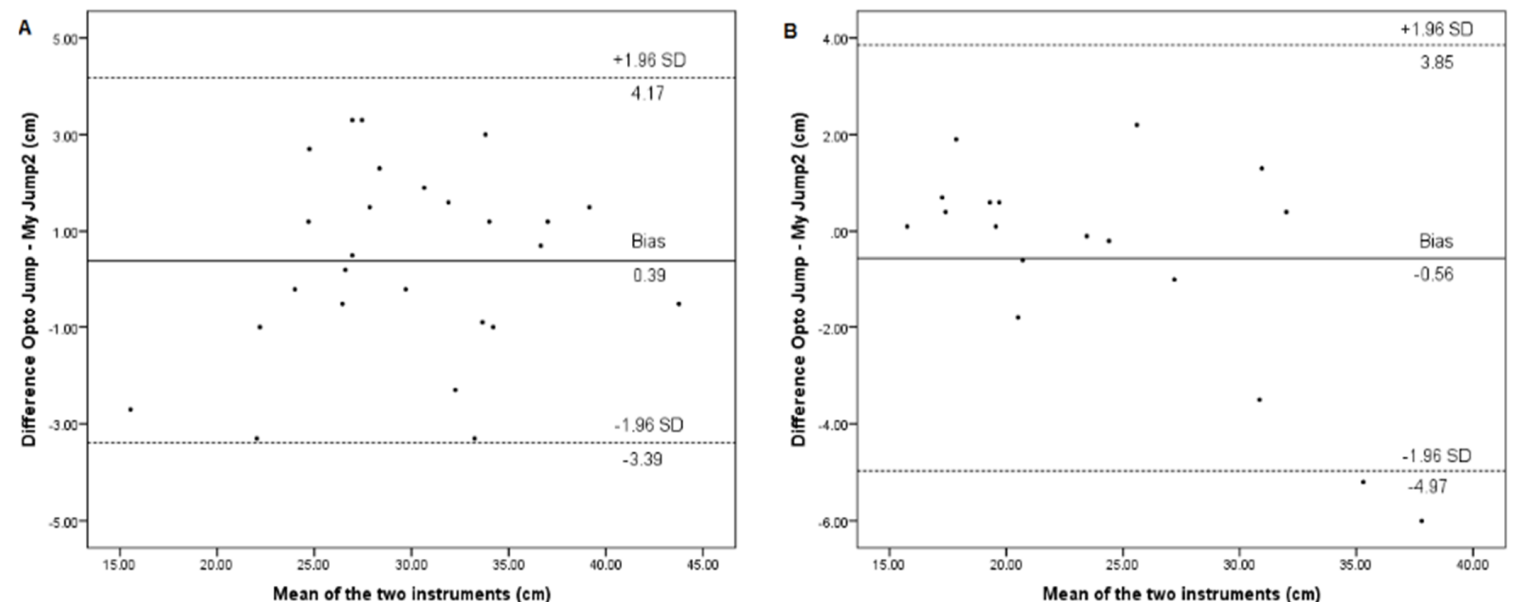

Figure 2. Level of agreement (Bland-Altman) with $95 \%$ limits of agreement (dashed lines) and the mean difference (solid line) between My Jump 2 and the Optojump for SJ in (A) male and (B) female participants.
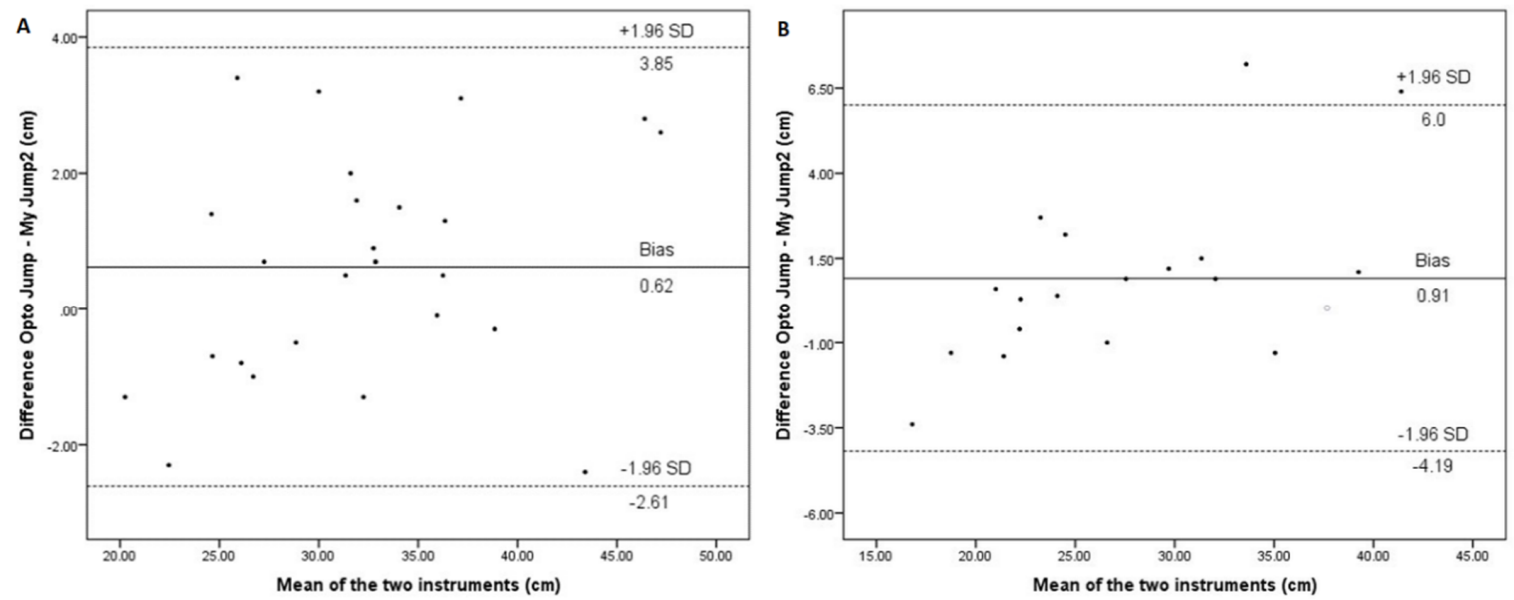

Figure 3. Level of agreement (Bland-Altman) with $95 \%$ limits of agreement (dashed lines) and the mean difference (solid line) between My Jump 2 and the Optojump for CMJ in (A) male and (B) female participants.
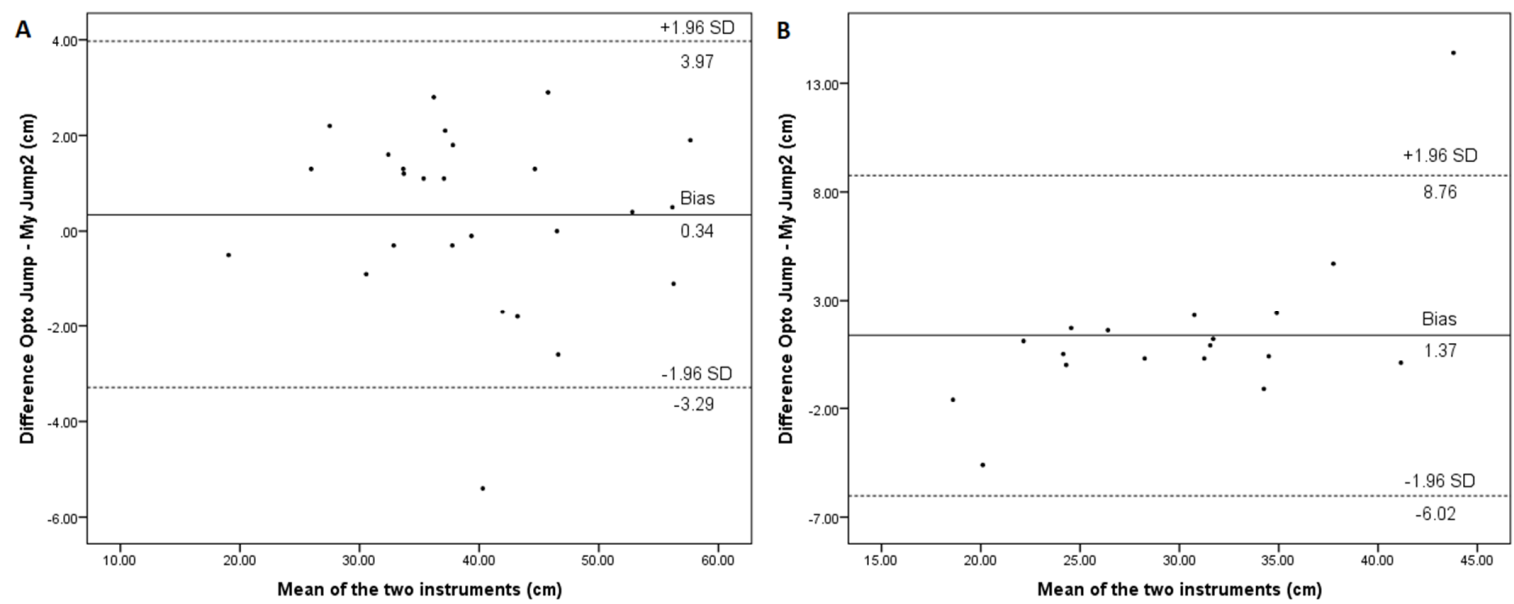

Figure 4. Level of agreement (Bland-Altman) with 95\% limits of agreement (dashed lines) and the mean difference (solid line) between My Jump 2 and the Optojump for CMJAS in (A) male and (B) female participants. 


\section{Discussion}

The CMJ and SJ tests have been strongly recommended to researchers and health practitioners. However, there is a great variety of testing methods and devices, and the majority of them are expensive and nonportable. The present study examined the concurrent validity and test-retest reliability of My Jump 2 installed on an iPhone $X$ compared to a validated Optojump instrument for measuring jump performance during SJ, CMJ, and CMJAS in recreationally active males and females. My Jump 2 was found to be highly valid and reliable in determining the jump height of an SJ, CMJ, and CMJAS in comparison with an Optojump. Moreover, CMJ and CMJAS tests showed to be practically useful to assess and monitor vertical jump performance in recreationally active adults. Furthermore, the data presented in Bland-Altman plots (Figures 2-4), show that most of the values are close to the mean of the differences between instruments, thereby representing a high level of agreement [27]. The plot shows a systematic bias (Figures 2-4) such that, across all jump heights, values derived from the Optojump tended to be slightly higher than those from My Jump 2 app (resulting in positive difference scores). The mean bias between My Jump 2 and the Optojump for jump height was less than $0.9 \mathrm{~cm}$. According to the authors knowledge, this is the first study to compare these two instruments. However, the low bias obtained in our study is in agreement with previous studies (mean bias: 0.2-1.1 cm) that compared My Jump app with force platform $[15,28,29]$. Higher bias $(1.37 \mathrm{~cm})$ was found only in females for CMJAS, which could be due to higher variability influenced by the lack of proper technique among females.

Our test-retest design in the group of recreationally active males and females revealed that $\mathrm{SJ}$, CMJ, and CMJAS appear as reliable assessment outcomes (ICC > 0.90), with slightly greater variability $(\mathrm{CV}>5 \%)$ for SJ outcomes between two sessions. The current results showed mean differences of $0.3-2.3 \mathrm{~cm}$ in all jumps for both males and females. This is in line with a mean difference of $0.43 \mathrm{~cm}$ for CMJ reported in recreationally active adults on My Jump app [22].

The concurrent validity of SJ, CMJ, and CMJAS was assessed by comparing outcome measures to the Optojump, which is already validated for estimating vertical jump. Very large correlations were observed between My Jump 2 app and Optojump in both, the male $(r=0.95-0.98)$ and female $(r=0.94-0.97)$, recreationally active adults. Most studies have compared My Jump app with force platform on several different jumps $[8,15,28]$. The abovementioned studies showed nearly perfect correlation $(r=0.97-0.99)$ for CMJ and SJ in trained athletes $[15,28]$, but also for drop jumps $(r=0.94-0.97)$ in sport science students [8]. The mean differences found in previous validity studies for CMJ performance that compared portable measurement devices with force plates were between $-1.06 \mathrm{~cm}$ and $11.7 \mathrm{~cm}[18,30,31]$. Regarding the My Jump app, Gallardo-Fuentes et al. [28] found a small mean difference between devices $(0.1 \mathrm{~cm})$ when testing CMJ and SJ jump in both male and female athletes. In one recent study [22] on recreationally active males and females, the mean difference in CMJ between devices was $0.21 \mathrm{~cm}$, which is slightly lower than the mean difference found in our study for SJ and CMJ $(0.4-0.9 \mathrm{~cm})$. As mentioned earlier, concurrent validity studies have compared My Jump to force plate data. However, it was also important to examine the validity of My Jump compared to a more frequently used field measurement tool. Optojump has also been found to be a valid and reliable vertical jump measurement tool [18], that is amenable to multiple testing locations and, thus, is more commonly used in different vertical jump test settings.

From a practical perspective, the use of healthy recreational adults from across the general population, iPhone $\mathrm{X}$ with a $240 \mathrm{~Hz}$ high-speed camera, the relatively large number of participants, and field-testing conditions rather than a precise laboratory space all signify strengths of the current research. However, the main limitation was that we did not use force plate, which is considered as the "gold standard" in measuring vertical jump in various populations. Nevertheless, comparing My Jump app with Optojump is more appropriate because both use the flight time to measure jump height. Additionally, different methods for determining the height of the vertical jump exist, which can also impact the validity of instruments [32]. Most of the research has compared methods that calculate jump height to methods that calculate flight distance. Struzik and Zawadzki [33] mention a method based on a force-displacement curve. The method used to calculate jump height should be determined by the equipment available and the definition of jump height used by the practitioner [34]. 
Furthermore, a possible limitation of our study was that some participants might not have been familiar with the SJ jump style and the usage of hands in CMJAS test, especially among female participants. Relatively high variability obtained in SJ may be due to a lack of proper technique among recreational athletes, while previous research was conducted on elite athletes [28] with greater experience performing these jumps.

Additionally, in comparison to male participants, females have a little difference in achieved jump height between CMJ and CMJAS. We can speculate that females did not swing with their arms correctly and use them to enhance their jump performance. During this jump, the arms reduce the pressure on the ground by moving downward toward the ground, which creates a negative effect, and later the arm swing creates a positive effect by moving upward and increasing the pressure on the ground [35]. Optimal jump is performed when the arms move in the jumping movement direction [36]. Additionally, female athletes show the trend for the increased differences in jump height between the two devices with increasing jumping height, which was confirmed by Attia et al. [37].

Furthermore, another limitation was that we did not check for the inter-rater reliability because some factors could contribute to differences in scores (i.e., the experience of the tester, the different variability of scores, testers' seat position, and assessment view angle) [38]. Therefore, future study should include a larger number of observers to compare results and to account for probable human error. Nevertheless, our results support the usage of smartphone apps in measuring vertical jump in recreationally active males and females. Due to its advanced technology, popularity, low cost, and portability, smartphone apps will soon be commonplace for measuring variables associated with physical fitness and health with great precision [39].

\section{Conclusions}

The results of present research suggest that smartphone app My Jump 2 is a valid, reliable, and useful tool for measuring jump height in recreationally active adults. Therefore, in addition to its affordable price compared with several available reference methods and given its simplicity and practicality, it can be used by practitioners, coaches, and recreationally-active adults to evaluate physical fitness with a robust and simple test as SJ, CMJ, and CMJAS.

Author Contributions: Conceptualization, Š.B. and N.T.; methodology, N.T.; software, S.A.; validation, M.P., S.A. and N.T.; formal analysis, M.P.; investigation, S.A.; resources, S.A.; writing一 original draft preparation, Š.B.; writing-review and editing, N.T.; visualization, Š.B.; supervision, M.P. All authors have read and agreed to the published version of the manuscript.

Funding: This research received no external funding.

Conflicts of Interest: The authors declare no conflict of interest.

\section{References}

1. WHO. Global Recommendations on Physical Activity for Health; WHO: Geneva, Switzerland, 2015.

2. Watkins, C.M.; Barillas, S.R.; Wong, M.A.; Archer, D.C.; Dobbs, I.J.; Lockie, R.G.; Coburn, J.W.; Tran, T.T.; Brown, L.E. Determination of Vertical Jump as a Measure of Neuromuscular Readiness and Fatigue. J. Strength Cond. Res. 2017, 31, 3305-3310. [CrossRef] [PubMed]

3. Spiteri, T.; Binetti, M.; Scanlan, A.T.; Dalbo, V.J.; Dolci, F.; Specos, C. Physical Determinants of Division 1 Collegiate Basketball, Women's National Basketball League, and Women's National Basketball Association Athletes: With Reference to Lower-Body Sidedness. J. Strength Cond. Res. 2019, 33, 159-166. [CrossRef] [PubMed]

4. Yingling, V.R.; Castro, D.A.; Duong, J.T.; Malpartida, F.J.; Usher, J.R.; Jenny, O. The reliability of vertical jump tests between the Vertec and My Jump phone application. PeerJ 2018, 2018, e4669. [CrossRef] [PubMed]

5. Aragón, L.F. Evaluation of Four Vertical Jump Tests: Methodology, Reliability, Validity, and Accuracy. Meas. Phys. Educ. Exerc. Sci. 2000, 4, 215-228. [CrossRef]

6. Gathercole, R.J.; Stellingwerff, T.; Sporer, B.C. Effect of acute fatigue and training adaptation on countermovement jump performance in elite snowboard cross athletes. J. Strength Cond. Res. 2015, 29, 37-46. [CrossRef] [PubMed] 
7. Castagna, C.; Ganzetti, M.; Ditroilo, M.; Giovannelli, M.; Rocchetti, A.; Manzi, V. Concurrent validity of vertical jump performance assessment systems. J. Strength Cond. Res. 2013, 27, 761-768. [CrossRef]

8. Haynes, T.; Bishop, C.; Antrobus, M.; Brazier, J. The validity and reliability of the My Jump 2 app for measuring the reactive strength index and drop jump performance. J. Sports Med. Phys. Fit. 2019, 59, $253-258$. [CrossRef]

9. Whitmer, T.D.; Fry, A.C.; Forsythe, C.M.; Andre, M.J.; Lane, M.T.; Hudy, A.; Honnold, D.E. Accuracy of a vertical jump contact mat for determining jump height and flight time. J. Strength Cond. Res. 2015, 29, 877-881. [CrossRef]

10. Pueo, B.; Lipinska, P.; Jiménez-Olmedo, J.M.; Zmijewski, P.; Hopkins, W.G. Accuracy of jump-mat systems for measuring jump height. Int. J. Sports Physiol. Perform. 2017, 12, 959-963. [CrossRef]

11. Carlos-Vivas, J.; Martin-Martinez, J.P.; Hernandez-Mocholi, M.A.; Perez-Gomez, J. Validation of the iPhone app using the force platform to estimate vertical jump height. J. Sports Med. Phys. Fit. 2018, 58, 227-232.

12. Bosquet, L.; Berryman, N.; Dupuy, O. A comparison of 2 optical timing systems designed to measure flight time and contact time during jumping and hopping. J. Strength Cond. Res. 2009, 23, 2660-2665. [CrossRef] [PubMed]

13. Cruvinel-Cabral, R.M.; Oliveira-Silva, I.; Medeiros, A.R.; Claudino, J.G.; Jiménez-Reyes, P.; Boullosa, D.A. The validity and reliability of the "my Jump App" for measuring jump height of the elderly. PeerJ 2018, 2018. [CrossRef] [PubMed]

14. Coswig, V.; Silva, A.D.A.C.E.; Barbalho, M.; de Faria, F.R.; Nogueira, C.D.; Borges, M.; Buratti, J.R.; Vieira, I.B.; Román, F.J.L.; Gorla, J.I. Assessing the validity of the MyJUMP2 app for measuring different jumps in professional cerebral palsy football players: An experimental study. JMIR mHealth uHealth 2019, 7, e11099. [CrossRef] [PubMed]

15. Balsalobre-Fernández, C.; Glaister, M.; Lockey, R.A. The validity and reliability of an iPhone app for measuring vertical jump performance. J. Sports Sci. 2015, 33, 1574-1579. [CrossRef] [PubMed]

16. Hopkins, W.G.; Schabort, E.J.; Hawley, J.A. Reliability of power in physical performance tests. Sport. Med. 2001, 31, 211-234. [CrossRef]

17. Brooks, E.R.; Benson, A.C.; Bruce, L.M. Novel Technologies Found to be Valid and Reliable for the Measurement of Vertical Jump Height With Jump-and-Reach Testing. J. Strength Cond. Res. 2018, 32, 2838-2845. [CrossRef]

18. Glatthorn, J.F.; Gouge, S.; Nussbaumer, S.; Stauffacher, S.; Impellizzeri, F.M.; Maffiuletti, N.A. Validity and reliability of optojump photoelectric cells for estimating vertical jump height. J. Strength Cond. Res. 2011, 25, 556-560. [CrossRef]

19. Samozino, P.; Morin, J.B.; Hintzy, F.; Belli, A. A simple method for measuring force, velocity and power output during squat jump. J. Biomech. 2008, 41, 2940-2945. [CrossRef]

20. Holsgaard Larsen, A.; Caserotti, P.; Puggaard, L.; Aagaard, P. Reproducibility and relationship of single-joint strength vs multi-joint strength and power in aging individuals. Scand. J. Med. Sci. Sport. 2007, 17, 43-53. [CrossRef]

21. Bosco, C.; Luhtanen, P.; Komi, P.V. A simple method for measurement of mechanical power in jumping. Eur. J. Appl. Physiol. Occup. Physiol. 1983, 50, 273-282. [CrossRef]

22. Stanton, R.; Wintour, S.A.; Kean, C.O. Validity and intra-rater reliability of MyJump app on iPhone $6 \mathrm{~s}$ in jump performance. J. Sci. Med. Sport 2017, 20, 518-523. [CrossRef] [PubMed]

23. Hopkins, W. Reliability from consecutive pairs of trials (Excel spreadsheet). A new view of statistics. sportsci.org: Internet Society for Sport Science.-Open Access Library. Internet Soc. Sport Sci. 2007, 11, $23-36$.

24. Koo, T.K.; Li, M.Y. A Guideline of Selecting and Reporting Intraclass Correlation Coefficients for Reliability Research. J. Chiropr. Med. 2016, 15, 155-163. [CrossRef] [PubMed]

25. Buchheit, M.; Lefebvre, B.; Laursen, P.B.; Ahmaidi, S. Reliability, usefulness, and validity of the 30-15 Intermittent Ice Test in young elite ice hockey players. J. Strength Cond. Res. 2011, 25, 1457-1464. [CrossRef] [PubMed]

26. Hopkins, W. How to Interpret Changes in an Athletic Performance Test. Sportscience 2004, 8, 1-7.

27. Bland, M.J.; Altman, D. Statistical Methods for Assessing Agreement Between Two Methods of Clinical Measurement. Lancet 1986, 327, 307-310. [CrossRef]

28. Gallardo-Fuentes, F.; Gallardo-Fuentes, J.; Ramírez-Campillo, R.; Balsalobre-Fernández, C.; Martínez, C.; Caniuqueo, A.; Cañas, R.; Banzer, W.; Loturco, I.; Nakamura, F.Y.; et al. Intersession and intrasession reliability 
and validity of the my jump app for measuring different jump actions in trained male and female athletes. J. Strength Cond. Res. 2016, 30, 2049-2056. [CrossRef]

29. Driller, M.; Tavares, F.; McMaster, D.; O’Donnell, S. Assessing a smartphone application to measure counter-movement jumps in recreational athletes. Int. J. Sports Sci. Coach. 2017, 12, 661-664. [CrossRef]

30. Choukou, M.A.; Laffaye, G.; Taiar, R. Reliability and validity of an accele-rometric system for assessing vertical jumping performance. Biol. Sport 2014, 31, 55-62. [CrossRef]

31. Buckthorpe, M.; Morris, J.; Folland, J.P. Validity of vertical jump measurement devices. J. Sports Sci. 2012, 30, 63-69. [CrossRef]

32. Wade, L.; Lichtwark, G.A.; Farris, D.J. Comparisons of laboratory-based methods to calculate jump height and improvements to the field-based flight-time method. Scand. J. Med. Sci. Sport. 2020, 30, 31-37. [CrossRef] [PubMed]

33. Struzik, A.; Zawadzki, J. Estimation of potential elastic energy during the countermovement phase of a vertical jump based on the force-displacement curve. Acta Bioeng. Biomech. 2019, 21, 153-160.

34. Moir, G.L. Three Different Methods of Calculating Vertical Jump Height from Force Platform Data in Men and Women. Meas. Phys. Educ. Exerc. Sci. 2008, 12, 207-218. [CrossRef]

35. Lees, A.; Barton, G. The interpretation of relative momentum data to assess the contribution of the free limbs to the generation of vertical velocity in sports activities. J. Sports Sci. 1996, 14, 503-511. [CrossRef] [PubMed]

36. Hara, M.; Shibayama, A.; Arakawa, H.; Fukashiro, S. Effect of arm swing direction on forward and backward jump performance. J. Biomech. 2008, 41, 2806-2815. [CrossRef] [PubMed]

37. Attia, A.; Dhahbi, W.; Chaouachi, A.; Padulo, J.; Wong, D.P.; Chamari, K. Measurement errors when estimating the vertical jump height with flight time using photocell devices: The example of Optojump. Biol. Sport 2017, 34, 63-70. [CrossRef]

38. Bučar, M.; Čuk, I.; Pajek, J.; Karacsony, I.; Leskošek, B. Reliability and validity of judging in women's artistic gymnastics at University Games 2009. Eur. J. Sport Sci. 2012, 12, 207-215. [CrossRef]

39. Bort-Roig, J.; Gilson, N.D.; Puig-Ribera, A.; Contreras, R.S.; Trost, S.G. Measuring and influencing physical activity with smartphone technology: A systematic review. Sport. Med. 2014, 44, 671-686. [CrossRef]

(C) 2020 by the authors. Licensee MDPI, Basel, Switzerland. This article is an open access article distributed under the terms and conditions of the Creative Commons Attribution (CC BY) license (http://creativecommons.org/licenses/by/4.0/). 